\title{
Simulation of Temperature Stratification in Atriums: Validation of Basic Model Features
}

\author{
Susan Bajracharya \\ Department of Mechanical of Engineering, Central Campus, Pulchowk, IOE, TU, Lalitpur, Nepal \\ Corresponding Email: bajracharya.susan@yahoo.com
}

\begin{abstract}
Data on climate conditions, internal temperature conditions and building features were used to deter mine the relative effect of building features on heat gains and losses in a naturally ventilated atrium located at Groningen, Netherlands. Temperature estimates obtained by simulation were compared with measured data. It was found that food estimates of thermal stratification could be obtained by dividing the atrium into horizontal subzones. Mass flow modeling and time steps of less than one hour were found to be important features.
\end{abstract}

\section{Introduction}

Experimental research has shown that temperature stratification and buoyancy-driven air flow significant characteristics of the thermal behavior of atriums $[2,10]$.Temperature stratification is a temperature difference between the temperature at any two levels (usually highest and lowest) in and enclosed space. The height of most atria combined with the solar gain they experience contributes to more extreme temperature stratification than in typical commercial and institutional spaces, which affects environmental control requirements and possibilities. Differences in densities between cooler and warmer air creates vertical pressure differences, resulting in air movement from the bottom to the top (known as stack effect), provide there are openings at the bottom and the top. Stack effect is more pronounced in cold climates, because of greater temperature differences between indoors and outdoors [8]. Simmonds showed that it is sufficient in some milder climates to provide passive ventilation and cooling in atria.

Computer modeling of these phenomena is useful in research and design. Some currently available computer programs for simulation the thermal performance of buildings can model energy use of a wide array of building systems over periods of a year of less, but are capable of simulation mass flow and temperature stratification (e.g., [7]). Others can be used to simulate mass flow and temperature stratification, but lack the capacity to model other energy-related phenomena (e.g. [11]).Some researchers have used computational fluid dynamics to model temperature stratification and air flow, but this approach has yet to be made widely available in programs that relate this feature to more general capabilities for modeling building energy systems. ESP-r (Environmental Systems Performance-research) is program that incorporates mass flow modeling capabilities, such as buoyancy-driven air flow [6], as well as other features that are interest in atria. These include the capacity to model radiative heat transfer between zones, including the transfer of solar radiation through as exterior zone to as adjacent zones. ESP-r incorporates more general capabilities for modeling building energy systems. The source code is open to public scrutiny, and there is a reasonably large international user community. The authors sought to evaluate the performance of ESP-r in modeling air flow and temperature stratification in atria. 
Experimentally-derived data acquired by other researchers were used to assess the accuracy with which atrium stratification and air flows could be modeled with ESP-r. The first aspect of this project was to determine the basic considerations in modeling there phenomena. The second aspect was validation of model enhancements to improve the match with experimental data (Bajracharya, 2014).

\section{The Experimental Data for the AZG Atrium}

A review of the literature revealed two studies for which extensive data of temperature stratification in atria were reported. One study $[10,11]$ provided data for an atrium in the AZG hospital complex at Groningen, Netherlands, hereafter referred to as the AZG atrium (Figure 1). The second study [2,9] provided data for a linear atrium in Ann Arbor, Michigan. All data were for sunny or mainly sunny days.

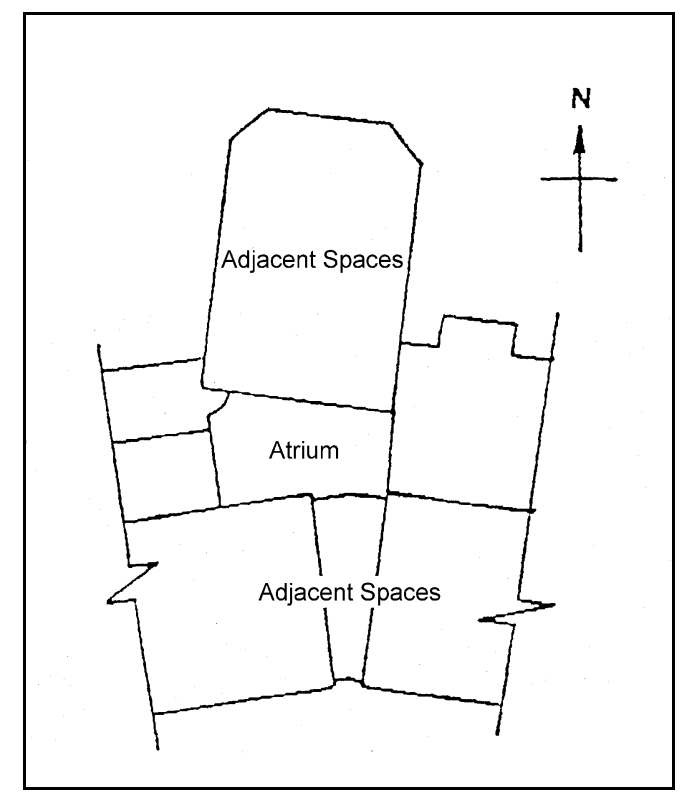

Figure 1: Plan of the AZG atrium

The data for the AZG atrium were used to establish the basic requirements for modeling atria with ESP-r, because there are fewer complication factors than for the atrium in Ann Arbor. (1) Neither the atrium, nor the wards adjacent to it are air-conditioned and (2) no mechanical heating was in use during the days on which measurements were made.

Groningen lies at $53.5^{\circ}$ north latitude and has a temperature climate. The atrium where temperature measurements were made has a floor area of $6,000 \mathrm{ft}^{3}\left(560 \mathrm{~m}^{2}\right)$ and is $60 \mathrm{ft}(20 \mathrm{~m})$ high. The volume of the atrium is about $400,000 \mathrm{ft}^{3}\left(11,200 \mathrm{~m}^{3}\right)$.The flat roof of the atrium is made of double-skinned PVC with 80 percent transmittance. Roof openings can provide a maximum net aperture of 7 percent of the roof area, or $430 \mathrm{ft}^{2}\left(40 \mathrm{~m}^{2}\right)$. The roof vents are normally operated on temperature control, but may also be manually controlled. No mechanical cooling is provided. The exterior walls are made of aluminium plate and concrete, with a cavity that was intended to accommodate insulation (not in place at the time the measurements were made).The linear atrium is used for circulation. Balconies opening from adjacent spaces 
overlook it. The atrium is bounded to its full height by a ward to the north and main hospital to the south. The atrium is bounded by circulation spaces at the first level only on the east and west sides. The upper east and west walls are exposed to exterior conditions.

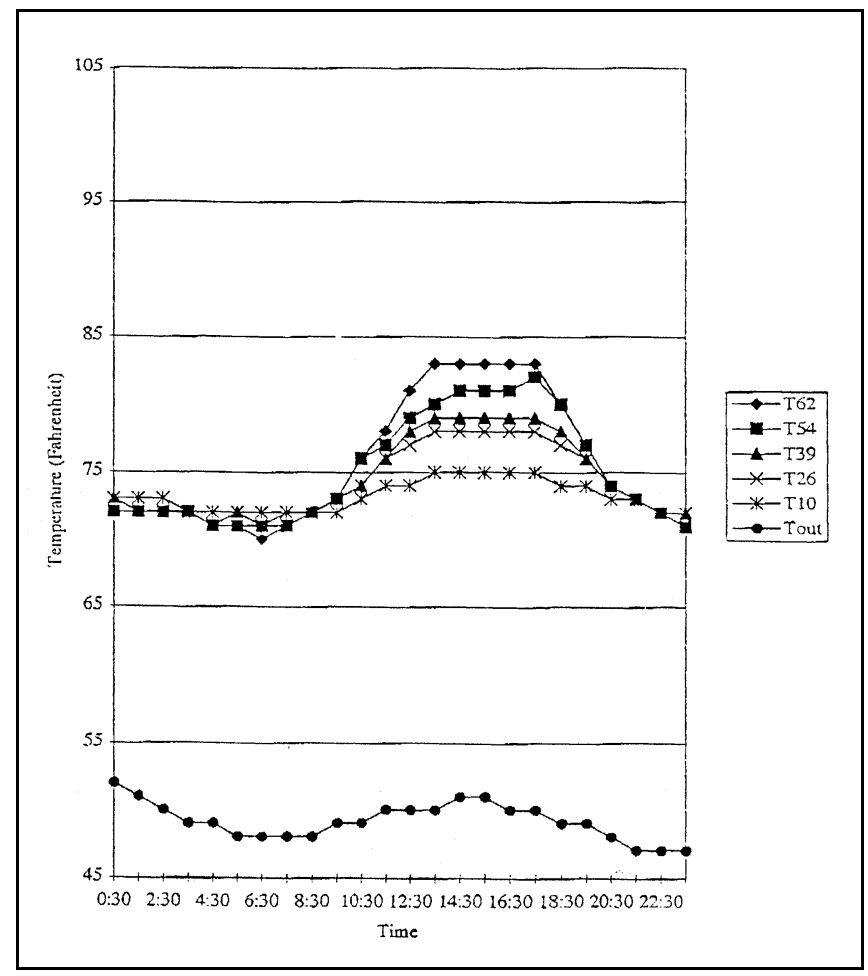

Figure 2: Temperatures measured at the AZG atrium on May 6, 1989 with roof vents closed

(The number after the "T" in the legend represents the heights above floor level.)

Measurements were reported for four days on which a variety of temperature conditions were experienced (Simmonds, 1994). On a spring day (May 6,1989) when the roof vents were closed, the maximum temperature stratification in the atrium reached about $9^{\circ} \mathrm{F}\left(5^{\circ} \mathrm{C}\right)$ with temperatures of $75^{\circ} \mathrm{F}\left(24^{\circ} \mathrm{C}\right)$ at the bottom point $(10 \mathrm{ft}(3 \mathrm{~m})$ above the floor $)$ and $84^{\circ} \mathrm{F}\left(29^{\circ} \mathrm{C}\right)$ at the top point (62ft (20m) above the floor) (Figure2) . On a warm summer day (June 12,1989), when roof vents were open, the maximum temperature stratification in the atrium reached about $7^{\circ} \mathrm{F}\left(4^{\circ} \mathrm{C}\right)$, with temperatures of $79^{\circ} \mathrm{F}\left(26^{\circ} \mathrm{C}\right)$ at the bottom and $86^{\circ} \mathrm{F}\left(30^{\circ} \mathrm{C}\right)$ at the top (Figure 3). During a hot summer day (July 7,1989) when the roof vents were open the maximum temperature stratification in the atrium reached about $7^{\circ} \mathrm{F}\left(4^{\circ} \mathrm{C}\right)$, with temperatures of $84^{\circ} \mathrm{F}\left(29^{\circ} \mathrm{C}\right)$ at the bottom and $91^{\circ} \mathrm{F}\left(33^{\circ} \mathrm{C}\right)$ at the top (Figure 4). During another warm summer day (August $20,1989)$, the maximum temperature stratification in the atrium reached about $16^{\circ} \mathrm{F}\left(9^{\circ} \mathrm{C}\right)$,with temperatures of $84^{\circ} \mathrm{F}\left(29^{\circ} \mathrm{C}\right)$ at the bottom point and $100^{\circ} \mathrm{F}\left(38^{\circ} \mathrm{C}\right)$ at the top, after the roof openings had been inadvertently left closed (Figure 5).

The meteorological data published on the AZG atrium included only outdoor temperatures. Fortunately, solar radiation data were available for meteorological station at Eelde, which is about $7 \mathrm{mil}(12 \mathrm{~km})$ from the center of Groningen. 


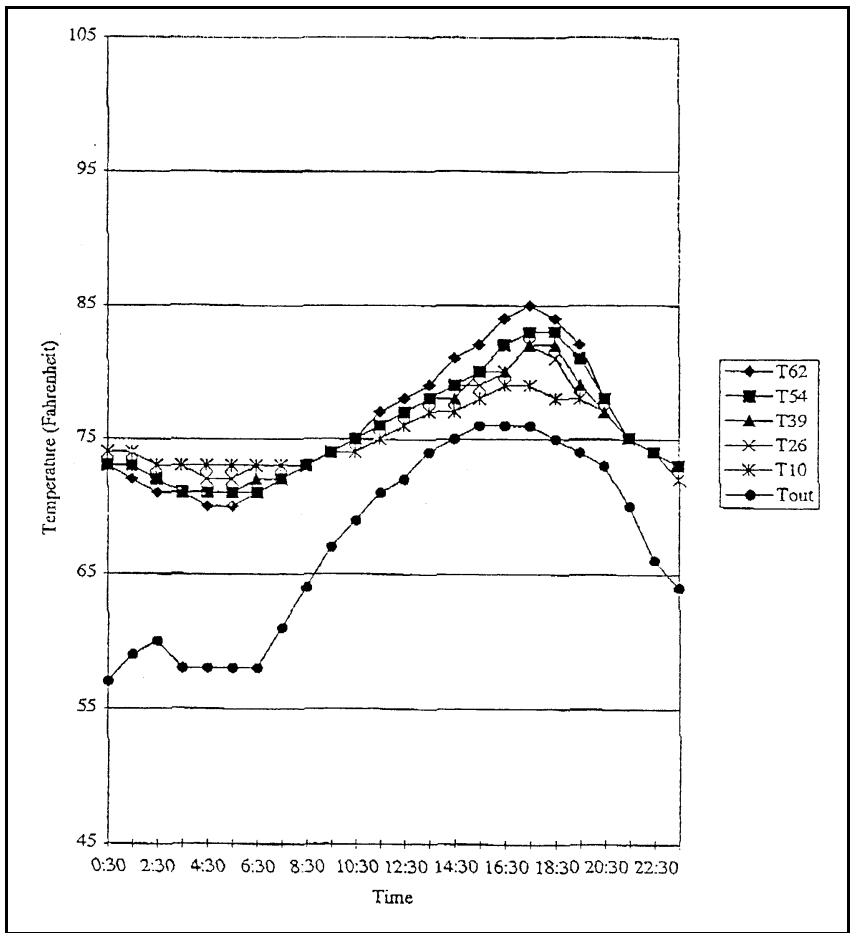

Figure 3: Temperatures measured at the AZG atrium on June 12, 1989 with roof vents open (The number after the " $T$ " in the legend represents the heights above floor level)

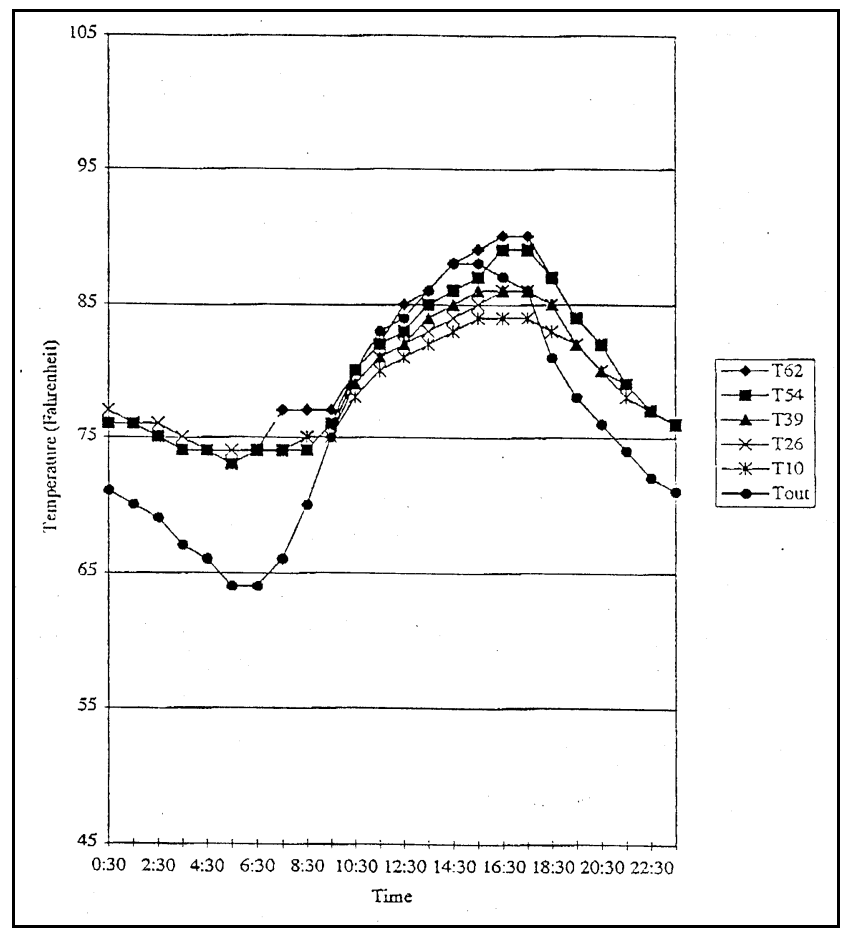

Figure 4: Temperatures measured at the AZG atrium on July 7, 1989 with roof vents open (The number after the "T" in the legend represents the heights above floor level) 


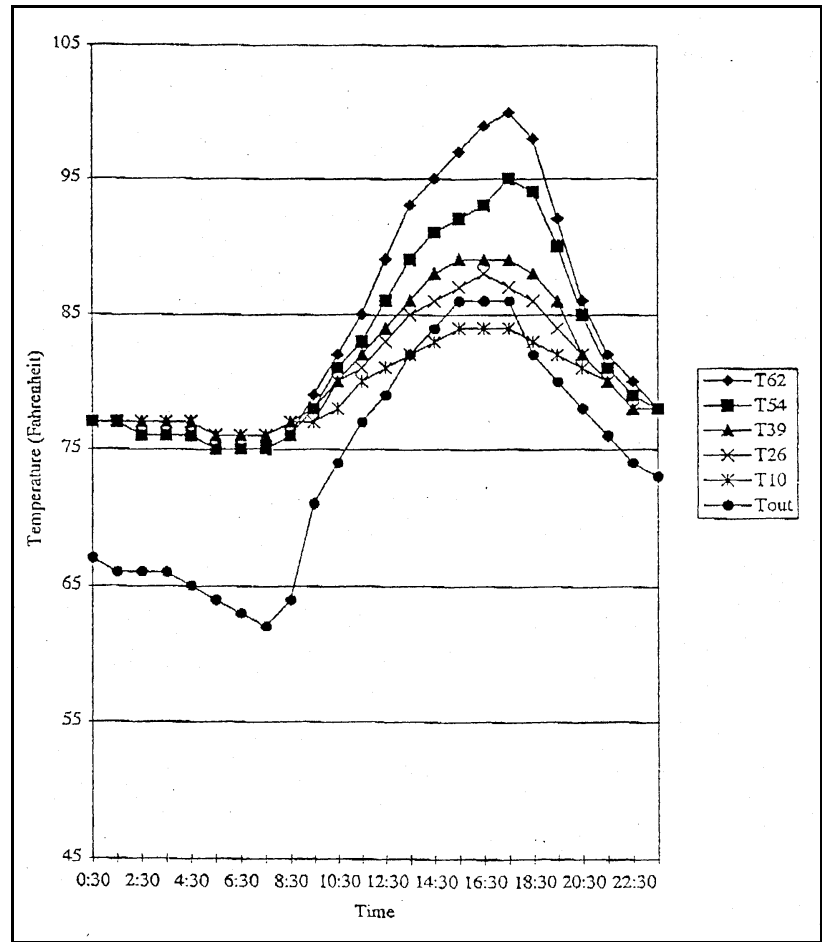

Figure 5: Temperatures measured at the AZG atrium on August 20, 1989 with roof vents closed (The number after the " $T$ " in the legend represents the heights above floor level)

\section{Modeling Mass Flow and Radiation Exchange in ESP-r}

In ESP-r, as in many programs for simulating building energy systems, a building is represented as a set of one or more zones. Each zone is given geometry. The surfaces are given thermal characteristics ("constructions"); the "constructions" are layers of "primitives". Transparent material constructions are a special class of constructions formed from primitives with thermal and solar-optical properties, such as transmittances dependent on the angle of incidence of light and solar radiation. The user may create primitives and/or constructions of use predefined elements. Heat transfers between zones are based on surface adjacencies established by the user. ESP-r allows the user to specify time steps between 1 minute and 1 hour.

Radiation exchange among zones occurs through "transparent material constructions". It is also possible to customize the thermal and optical properties of these surfaces. Options exist for the transfer of the energy from solar radiation received by a zone to its neighbors, including 1) diffuse radiation to all neighboring zones, 2) radiation divided among two user-designated adjacent zones, and 3) radiation allocated to single user-designated adjacent zone.

To model buoyancy-driven air flow, a mass flow network must be defined, including nodes and connections. The properties of nodes (e.g., height above a datum) and connections (e.g. type of orifice such as crack or large opening) are required. The nodes are assigned to zones in the building model. Nodes must also be established for the outdoor environment to model indooroutdoor air exchanges. 
ESP-r uses weather files that include data on air temperature, relative humidity, solar radiation and wind conditions. At least one "start-up" day is run in ESP-r to establish the dynamics of the modeling situation.

\section{AZG Atrium - Basic Thermal Parameters}

To gain a better understanding of the relative importance of the various thermal transfers, some basic manual calculations were carried out for conditions typical of the days for which measurements were reported.

Conduction heat transfer through the exterior and interior envelopes could be calculated using Equation (1).The radiation incident on the skylight could be approximated by Equation (2).The ventilation load could be estimated using Equation (3).

$$
\begin{aligned}
& \mathrm{q}_{\text {cond }}=\mathrm{U} A \Delta \mathrm{t} \\
& \mathrm{q}_{\mathrm{rad}}=\mathrm{G}_{\text {global }} \mathrm{A} \\
& \mathrm{q}_{\mathrm{vent}}=1200 \mathrm{Q} \Delta \mathrm{t}
\end{aligned}
$$

where

$\mathrm{q}_{\mathrm{cond}}=$ conductive heat transfer, Btu/h $\quad \mathrm{q}_{\mathrm{rad}}=$ radiative conductive hear transfer, Btu $/ \mathrm{h}$

$\mathrm{q}_{\mathrm{vent}}=$ ventilation load, Btu/h

$\mathrm{U}=$ overall heat transfer coefficient, Btu/h. $\mathrm{ft}^{2}{ }^{\circ} \mathrm{F}$

volume, $\mathrm{ft}^{3}$

$\mathrm{A}=$ area, $\mathrm{ft}^{2} \mathrm{~V}=$

$\mathrm{N}=$ air changes per hour, $\mathrm{ft}^{2}$

$\Delta \mathrm{t} \quad=$ maximum temperature difference for the data set, ${ }^{\circ} \mathrm{F}$

$\mathrm{G}_{\text {global }}=$ global radiation, Btu/h $\mathrm{ft}^{2}$

$\mathrm{Q}=$ airflow rate, $\mathrm{cfm}$

The peak conductive heat transfer through the exterior end walls will be about

$$
\mathrm{q}_{\mathrm{cond}}=\mathrm{U} A \Delta \mathrm{t}=(0.7)(4100)(2)(77-49)=16,000 \mathrm{Btu} / \mathrm{h}=5 \mathrm{~kW}
$$

The peak conductive heat transfer through the interior walls will be about

$$
\mathrm{q}_{\mathrm{cond}}=\mathrm{U} \text { A } \Delta \mathrm{t}=(0.29)(6200)(2)(82-72)=36,000 \mathrm{Btu} / \mathrm{h}=10 \mathrm{~kW}
$$

The peak conductive heat transfer through the skylight will be about

$$
\mathrm{q}_{\mathrm{cond}}=\mathrm{U} A \Delta \mathrm{t}=(0.49)(6000)(77-49)=82,000 \mathrm{Btu} / \mathrm{h}=24 \mathrm{~kW}
$$

The peak radiative energy incident on the skylight will be about

$$
\mathrm{q}_{\mathrm{rad}}=\mathrm{G}_{\text {global }} \mathrm{A}=(2200)(6000)=13,200,000 \mathrm{Btu} / \mathrm{h} \mathrm{ft} 2=390 \mathrm{~kW}
$$

The peak heat loss through ventilation for $1 \mathrm{ACH}$ will be about

$$
\mathrm{q}_{\mathrm{vent}}=1.08 \mathrm{nV} \Delta \mathrm{t}=(1.08)(1)(6580)(68-27)=291,000 \mathrm{Btu} / \mathrm{h}=85 \mathrm{~kW}
$$

The peak heat loss through ventilation for $6 \mathrm{ACH}$ (maximum ventilation rate) will be about

$$
\mathrm{q}_{\mathrm{vent}}=291,000 \mathrm{Btu} / \mathrm{h} \text { x } 6=1,750,000, \mathrm{Btu} / \mathrm{h}=510 \mathrm{~kW}
$$


Based on the calculations, it is evident that ventilation loads and heat gain from solar radiation will have the greatest effects, roughly by an order of magnitude. Night-time conductive heat transfer through the skylight is large relative to other flows through other surfaces, especially, in terms of thermal stratification, considering that the effects are concentrated at the top layer of air in the atrium. The conductive heat transfer through interior walls is relatively small, even if a relatively high $\mathrm{U}$-value is assumed, because of the relatively small temperature differences. The conductive heat transfer through exterior walls is relatively small because they have a smaller area and higher $\mathrm{U}$-value than the atrium roof.

\section{Single Zone Model of the AZG Atrium}

The AZG atrium was first modeled as a single zone. While this model could not provide information on thermal stratification (the air in each zone is thermodynamically homogeneous), this allowed comparison with results from some other studies and also allowed clarification of some of the modeling issues.

For purpose of simulation, the AZG atrium geometry was simplified to a rectangular plan (Figure 6) having the same floor area as the actual atrium.

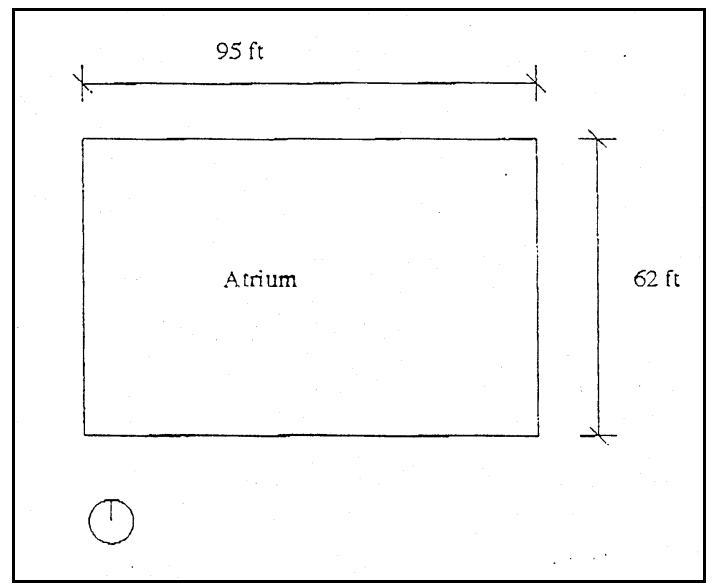

Figure 6: Plan of the AZG atrium as simplified for simulation

Simmonds [11] said that the PVC glazing had a transmittance of 0.82 .He also said that it was designed to exclude direct sunlight and admit diffuse skylight. However, he did not elaborate on this or give an overall solar transmittance value. It is likely that the structural support system and frames for the atrium floor obstructed at least 90 percent of the atrium opening, giving a net atrium transmittance of not more that about 0.70.Simulations were conducted with the default direct normal solar transmittance value of 0.611 for a double-glazed system. Sensitivity to this value is discussed [1]; the initial assumption was found to be satisfactory.

The walls facing east and west were modeled as opaque exterior walls (having thermal mass) with appropriate U-values for the described constructions, while walls facing north and south were modeled as partitions (having negligible thermal mass).The environment on the other side of these partition walls was specified as having a constant temperature of $7^{\circ} \mathrm{F}\left(2^{\circ} \mathrm{C}\right)$.

The control condition for the atrium was specified as free floating. Casual gains for occupancy and lighting were set at zero. 
The most basic model for the AZG atrium included only one zone-the atrium itself. This model gave estimates for night-time temperatures on May 6 that fell below $54 * \mathrm{~F}(12 * \mathrm{C})$ with outside air modeled as flowing directly into the atrium. In reality, the temperatures had remained above $68 * \mathrm{~F}\left(20^{*} \mathrm{C}\right)$ at all measurement points. Simmonds' (1993) had commented that " $70,000 \mathrm{~m} 3 / \mathrm{h}$ $(40,000 \mathrm{cfm})$ of air flows through the thoroughfares into the atrium, which is enough for 6 air changes. "Zones $Z_{\text {adjn }}$ and $Z_{\text {adjs }}$ were incorporated to model the effects of adjacent spaces in the hospital, from which warm air is drawn: a schematic of the mass flow network is shown in Figure 7.Two zones were added, because of limits in the amount of heat that could be added to the air passing through a single zone when some of the mass flow alternatives were evaluated.

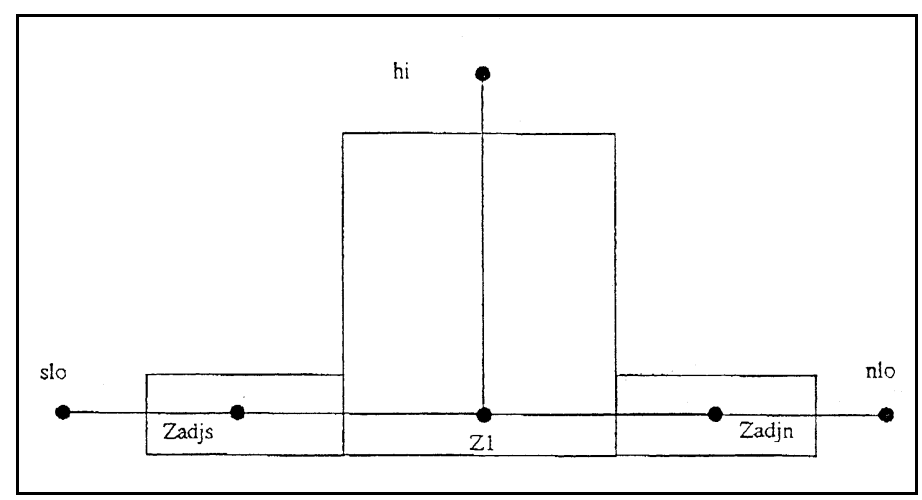

Figure 7: Sectional schematic showing the zones, mass flow nodes, and mass flow paths for the single zone AZG model

In defining the mass flow network, it was necessary to provide the size of the openings between connected volumes. This was known for the roof vents for days when they were open. However, on May and most of August 20 the roof vents were closed. Trial and error studies with the simulation model showed that an orifice of $22 \mathrm{ft} 2(2 \mathrm{~m} 2)$ yielded an air flow of about $1 \mathrm{ACH}$, which was consistent with Hejazi-Hashemi's observation regarding air change for an atrium with roof vents closed and open lower levels apertures (similar to the corridors connection with the atrium in the AZG hospital).

Time-series plots of computed (single zone model) and measured (highest and lowest points) temperatures on the four dates of interest are shown in Figures 8-11. The computed temperature is generally closes to the temperature for the highest measurement point. Other studies have also found that the temperatures predicted by single-zone models are closer to the upper level temperature that the lower level temperature [3].

To show the importance of the mass flow calculations, simulations were conducted without the mass flow network. Figure 12 and 13 show computed and measured temperatures for May 6 and June 12,respectively.The computed results for May 6 peak more than $9^{\circ} \mathrm{F}\left(5^{\circ} \mathrm{C}\right)$ higher that the measured value for the highest point, while the computed results for June 12 peak about $36^{\circ} \mathrm{F}$ $\left(20^{\circ} \mathrm{C}\right)$ higher than the measured value for the highest point. Note that use of the air change method in lieu of the mass flow model might have provided better daytime estimates, but would have produced worse night-time estimates (because the air is assumed to be drawn from outdoors, rather than from adjacent spaces). It should be noted at this point that variations in the time step between 10 and 60 min produced variations in temperature estimates of less than $2^{\circ} \mathrm{F}$ $\left(1^{\circ} \mathrm{C}\right)$. 


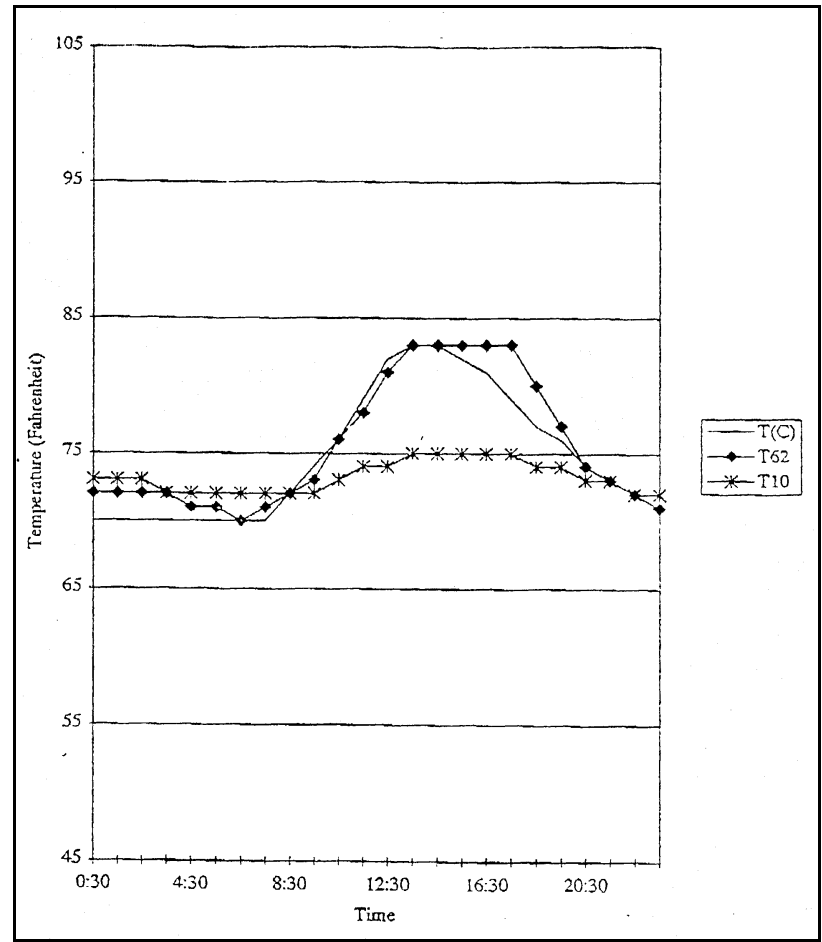

Figure 8: Time series plot of computed and measured temperatures in the AZG atrium on May 6, 1989; single zone model with mass flow

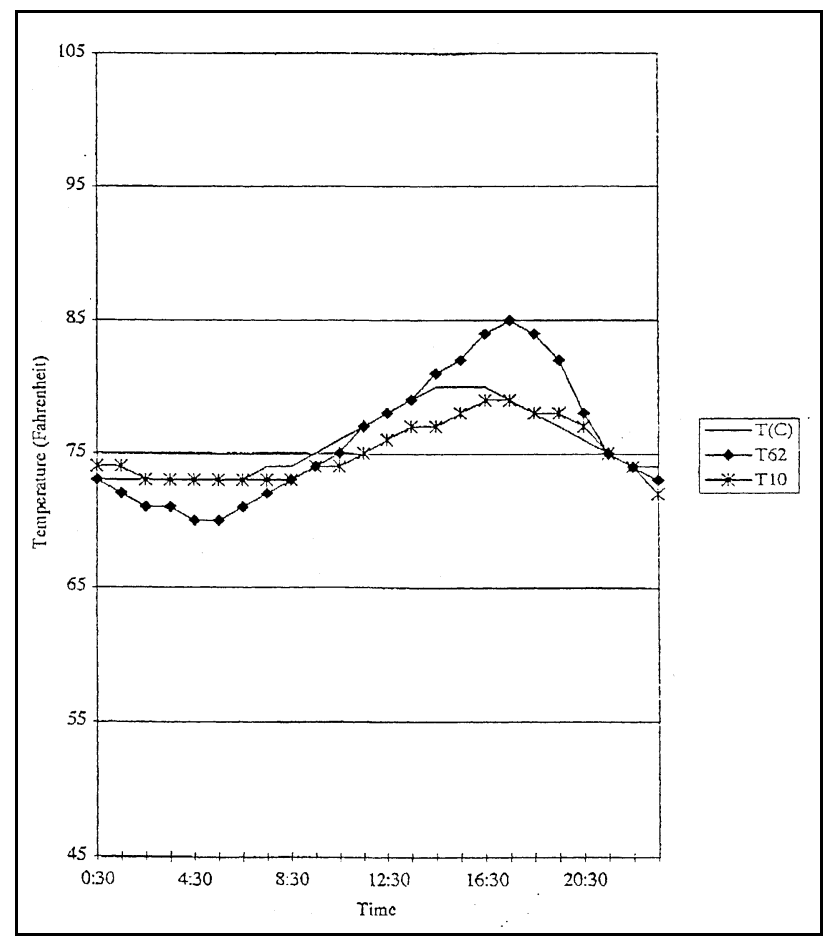

Figure 9: Time series plot of computed and measured temperatures in the AZG atrium on June 12, 1989; single zone model with mass flow 


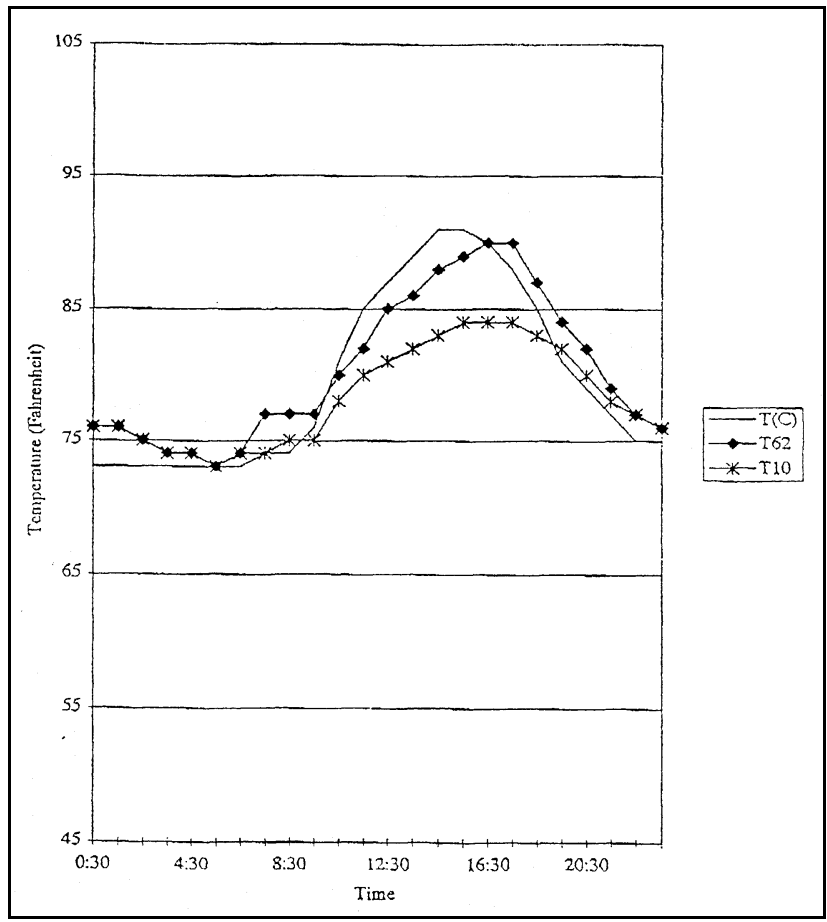

Figure 10: Time series plot of computed and measured temperatures in the AZG atrium on July 7, 1989; single zone model with mass flow

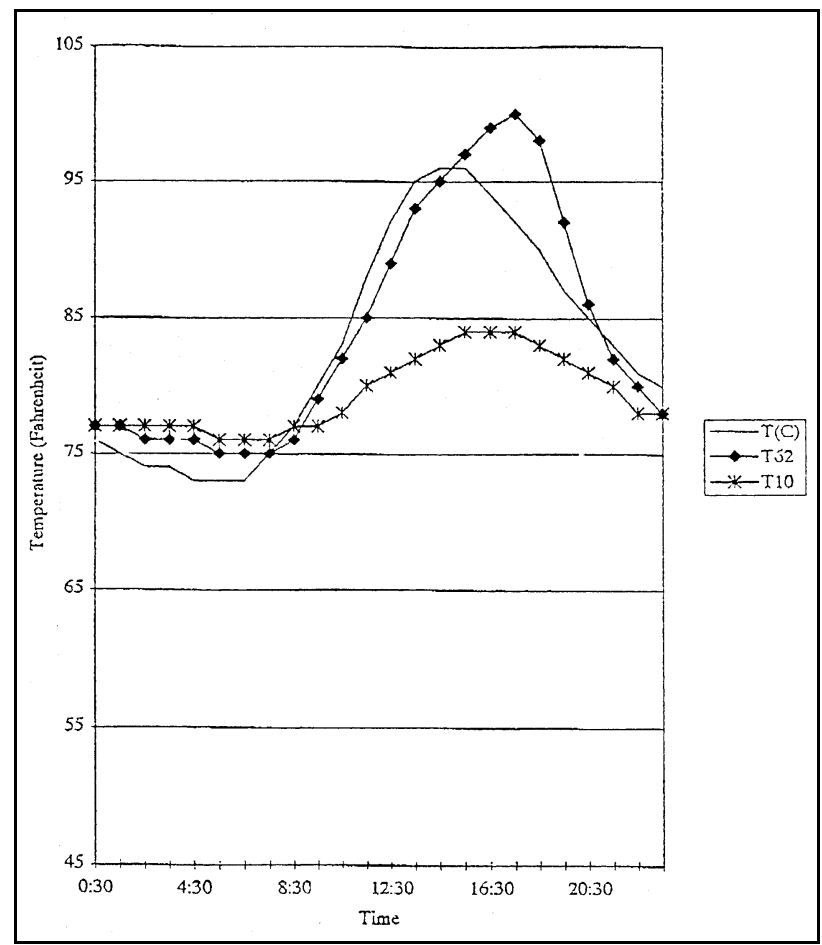

Figure 11: Time series plot of computed and measured temperatures in the AZG atrium on August 20, 1989; single zone model with mass flow 


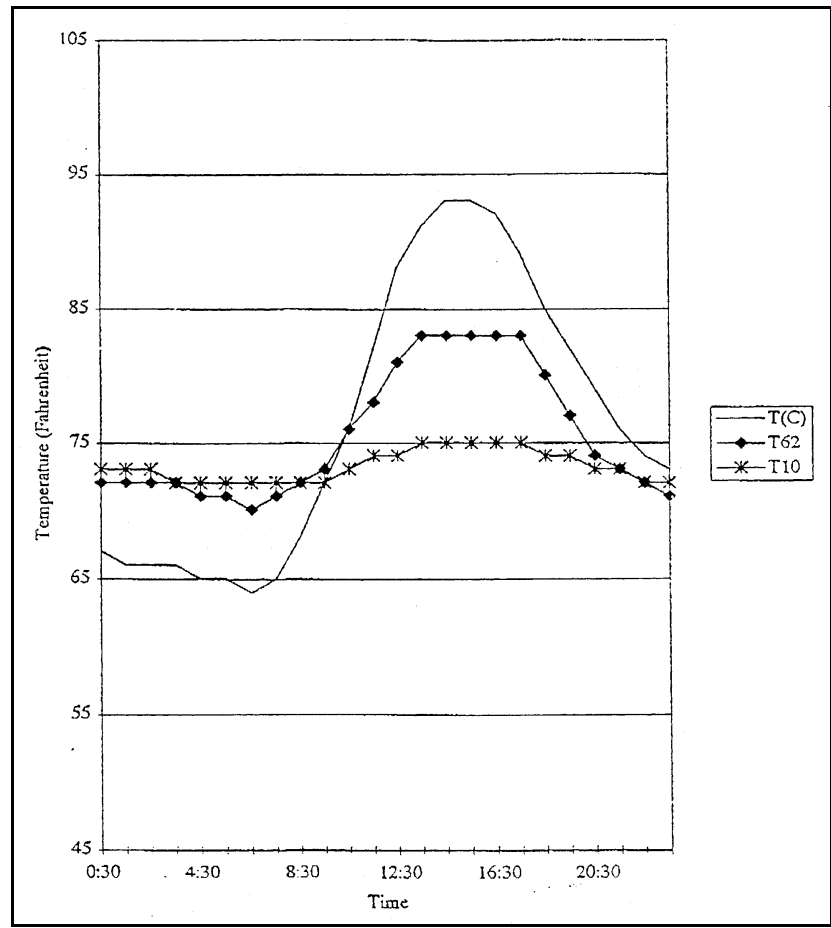

Figure 12: Time series plot of computed and measured temperatures in the AZG atrium on May 6, 1989; single zone model without mass flow

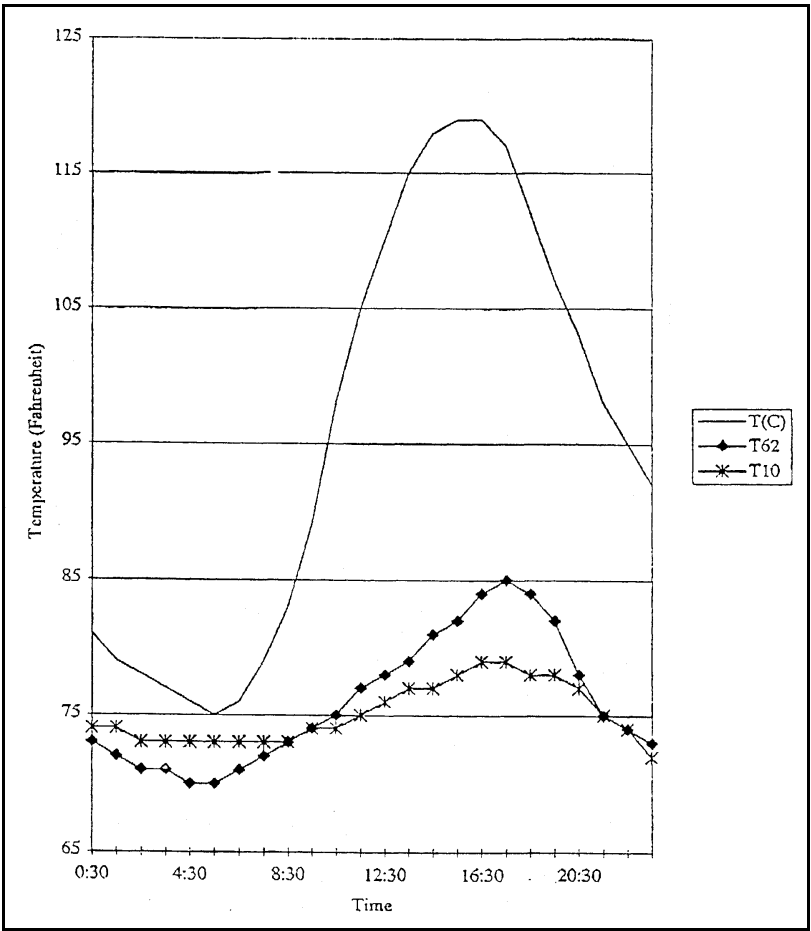

Figure 13: Time series plot of computed and measured temperatures in the AZG atrium on June 12, 1989; single zone model without mass flow 


\section{Five Zone Model of the AZG Atrium}

Hensen and Hamelinck [4] showed that temperature stratification in an office with displacement ventilation system could be modeled by dividing the office into horizontal subzones. This technique was applied to the AZG atrium (Figure 14).The five measurement points resulted in five subzones, so this will be referred to as the "five zone model."The temperature measurement points set up by [11] were unevenly distributed across the height of the atrium, so the dividing plane between atrium subzones was taken as the midpoint between measurement points. The surfaces between atrium subzones and specified as transparent surfaces with the maximum solar transmittances allowed by ESP-r ( 0.95 or greater) and very high U-values of about $0.5 \mathrm{Btu} / \mathrm{h}$ $\mathrm{ft}^{2 \circ} \mathrm{F}\left(2.7 \mathrm{~W} / \mathrm{m}^{2} \mathrm{~K}\right)$.Each subzone was associated with a node in the mass flow network, and was connected to adjacent zones by an orifice of $40 \mathrm{~m}^{2}$.

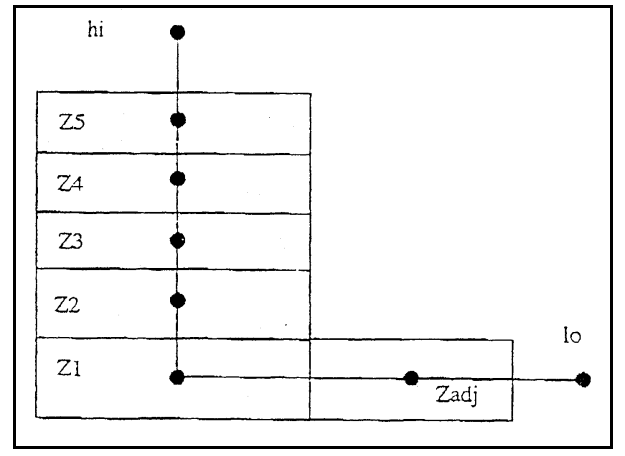

Figure 14: Sectional schematic showing the zones, mass flow nodes, and mass flow paths for the fize zone AZG model

A time-series plot of computed temperatures for May 6 and July 7 are shown in Figures 15 and 16. Note that the top level temperature tends to drop below the lower level temperatures at night, a trend also apparent in the measurements (Figures 2-5); presumably, this was due to the effect of the large night-time heat loss through the glazed roof of the top sub-zone of the atrium.

Initial simulations produced results in which top zone temperatures were excessively high; with the atrium divided into subzones, all solar radiation incident on the atrium was modeled as received by Z5, the top zone, when in reality, it would reach lower areas of the atrium during the middle of the day. As described above, ESP-r provides options for allocation of solar radiation received by a zone. Energy from solar radiation received by $Z_{5}$ was assigned to Z4.This provided a better match with measured data. Figure 17 shows one inconsistent effect of this in the July 7 results, in which the $Z_{4}$ temperature is computed to exceed the $Z 5$ temperature at 15:30 and effect that did not appear in any atrium measurements.

Simmonds [11] used a proprietary program, ROOM to "calculate the buoyancy-driven ventilation and stratified-temperature predictions."He provided time-series plots of computed and measured temperatures at $10 \mathrm{ft}(3 \mathrm{~m})$ above floor level for the June and July dates. Median and maximum temperature differences were determined from the values he published, and were found to be $3.9^{\circ} \mathrm{F}\left(2.1^{\circ} \mathrm{C}\right)$ and $8.5^{\circ} \mathrm{F}\left(4.7^{\circ} \mathrm{C}\right)$ for the June date and $0.9^{\circ} \mathrm{F}\left(0.5^{\circ} \mathrm{C}\right)$ and $7.6^{\circ} \mathrm{F}$ $\left(4.2^{\circ} \mathrm{C}\right)$ for the July date. The corresponding values from ESP-r were $-0.9^{\circ} \mathrm{F}\left(-0.5^{\circ} \mathrm{C}\right)$ and $-4.5^{\circ} \mathrm{F}$ $\left(-2.5^{\circ} \mathrm{C}\right)$ for the June date and $-3.6^{\circ} \mathrm{F}\left(-2^{\circ} \mathrm{C}\right)$ and $-5.4^{\circ} \mathrm{F}\left(-3^{\circ} \mathrm{C}\right)$ for the July date, so the ESP-r estimates were slightly more accurate. 


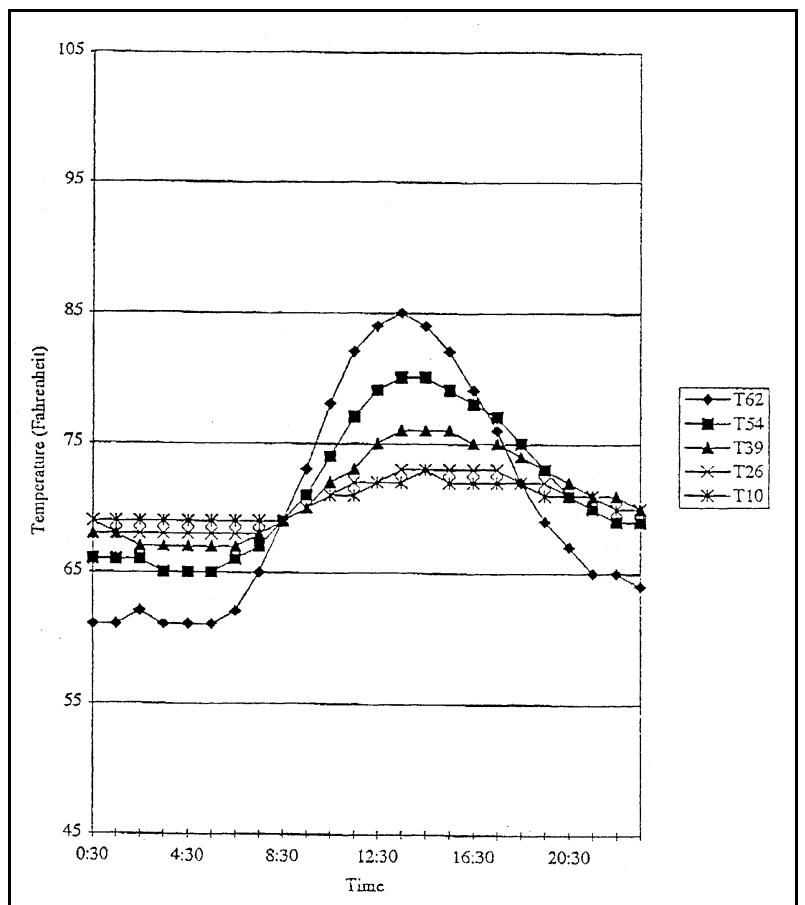

Figure 15: Time series plot of computed temperatures for the fize-zone AZG atrium model for May 6 at 10 min time step (The number after the " $\mathrm{T}$ " in the legend represents the heights above floor level)

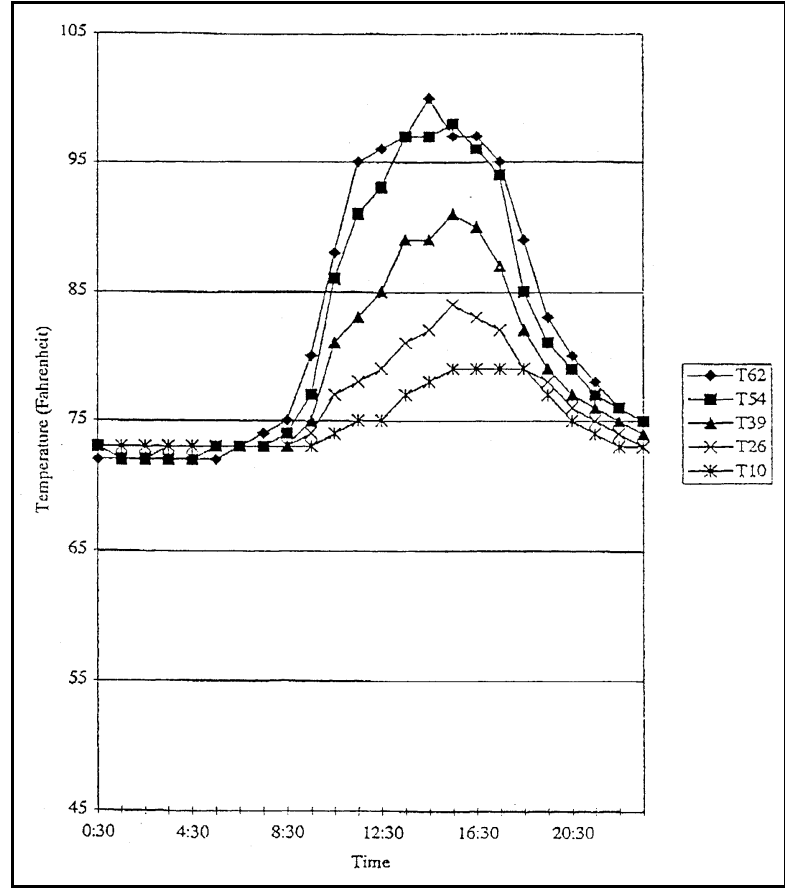

Figure 16: Time series plot of computed temperatures for the fize-zone AZG atrium model for July 7 at 10 min time step (The number after the " $\mathrm{T}$ " in the legend represents the heights above floor level) 


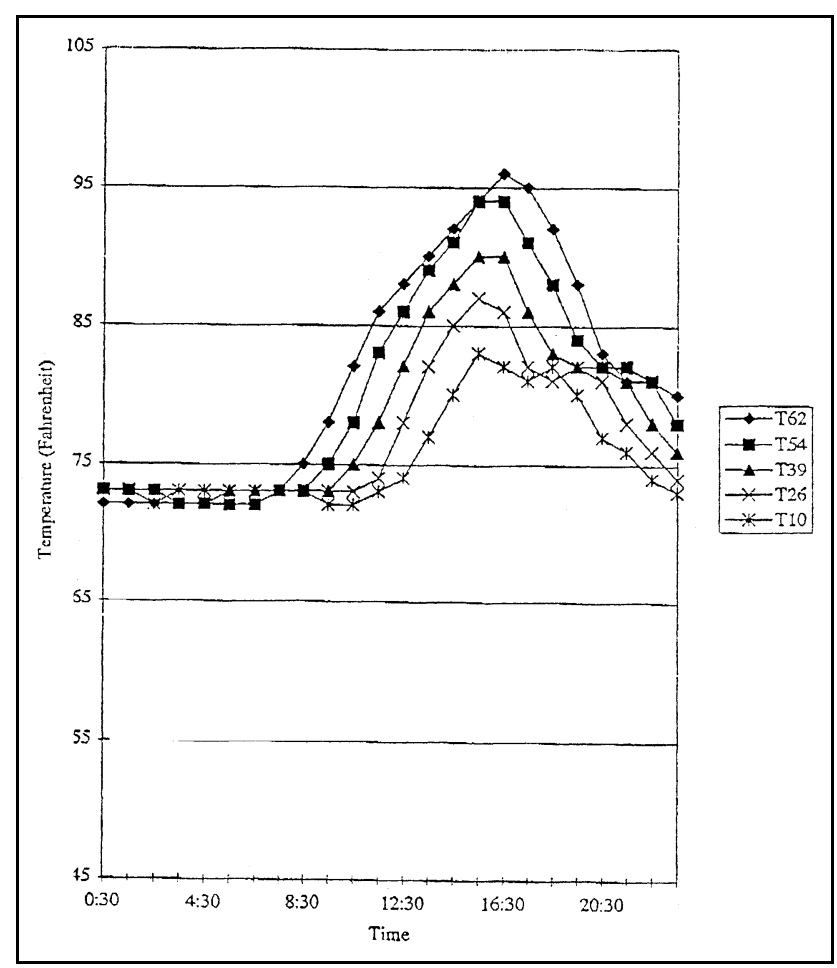

Figure 17: Time series plot of computed temperatures for the fize-zone AZG atrium model for July 7 at 60 min time step (The number after the " $T$ " in the legend represents the heights above floor level)

\section{Conclusions}

The results show that a fairly basic ESP-r model can simulate temperature stratification in an atrium with reasonable accuracy. Effective computer modeling of temperature stratification required (in addition to basic thermal transfers):

- A capacity to run simulations with time steps as low as $10 \mathrm{~min}$

- A mass flow modeling capability

- A capacity to transfer solar radiation beyond the first zone it strike

The process of validating the model showed the value of thermal behavior data for days with different climate conditions. A simulation model that provided good results for one day's weather data did not necessarily provide good results for another day's weather data. Validation studies for atrium modeling should therefore be based on experimental data for at least two days with substantially different weather conditions.

Researchers reporting experimental work on thermal performance of atriums should provide more complete data. In addition to outside temperatures, solar radiation conditions should be indicated. This should definitely include (at least) global irradiance and (preferably) diffuse irradiance or direct normal irradiance. Wind conditions should also be recorded. The solaroptical properties of exterior transparent envelopes are also very important, including (at least) transmittances (both glazing and overall envelope transmittance) and U-values. 
Modeling of atriums with a program such as ESP-r would be an extremely valuable complement to experimental work, especially if modeling was conducted in tandem with (or even beginning prior to) the experimental work. The simulation model would help in identifying factors that significantly affect performance and that should be monitored or otherwise recorded in the course of the experimental work.

\section{Acknowledgements}

Dr. Jan Hensen of the Energy Systems Research Unit of Strathclyde University provided extensive technical advice regarding modeling with ESP-r. Mr. Rene Bosboom of the Royal Netherlands Meteorological Institute provide solar radiation data for the Groningen area.

\section{References}

[1] Bajracharya, S. 2014. Simulation of thermal stratification in atria: effects of solar radiation.

[2] Jones, J.R and M.B Luther 1993. A summary of analytical methods and case study monitoring of atria. ASHRAE Transactions 99 (1).

[3] Hastings, R. (ed.) 1992. Passive solar commercial and institutional buildings Wiley and Sons.

[4] Hensen, J.L.M and M.J.H Hamelinck 1994. Energy simulation of displacement ventilation in offices. Building Services Engineering Research 16(2): 77-81.

[5] Hajazi-Hashemi, M.G. Energy simulation of displacement ventilation in offices. The advanced case study of the PI-Group Head Office.IEA Task XI Advanced Case Studies 87-103.

[6] Hensen, J.L.M 1991. On the thermal interaction of building structure and heating and ventilation system Dissertation University of Strathclyde.

[7] Landsberg D.R., H.P. Misuriello and S. Moreno. 1987. Design Strategies for energy-efficient atrium spaces. ASHRAE Report No.2996 (RP-315).

[8] Lovatt, J.E and A.G. Wilson 1994 Stack effect in tall buildings. ASHRAE Transactions 100 (2).

[9] Luther, M.B., J.R. Jones and A. Selamet. 1990. Atrium design and operation strategies. Proceedings of the $15^{\text {th }}$ Annual Conference of the American Solar Energy Society, Austin, Texas.

[10] Simmonds, P.1994. Experiences with naturally ventilate atria. ASHRAE Transactions 100 (1).

[11] Simmonds, P. 1993. Experiences with naturally ventilated atria. Proceedings of the CIBSE National Conference. Chartered Institute of Building Services Engineers 161-178. 